\title{
Corrigendum: Identification of cross-linked peptides from large sequence databases
}

Oliver Rinner, Jan Seebacher, Thomas Walzthoeni, Lukas Mueller, Martin Beck, Alexander Schmidt, Markus Mueller \& Ruedi Aebersold Nat. Methods 5, 315-318 (2008); published online 9 March 2008; corrected after print 27 June 2008.

In the version of this Brief Communication initially published, an author name (Lukas Mueller) was incorrect. The correct author name is Lukas N. Mueller. The error has been corrected in the HTML and PDF versions of the article.

\section{Corrigendum: BAC Transgene0mics: a high-throughput method for exploration of protein function in mammals}

Ina Poser, Mihail Sarov, James R A Hutchins, Jean-Karim Hériché, Yusuke Toyoda, Andrei Pozniakovsky, Daniela Weigl, Anja Nitzsche, Björn Hegemann, Alexander W Bird, Laurence Pelletier, Ralf Kittler, Sujun Hua, Ronald Naumann, Martina Augsburg, Martina M Sykora, Helmut Hofemeister, Youming Zhang, Kim Nasmyth, Kevin P White, Steffen Dietzel, Karl Mechtler, Richard Durbin, A Francis Stewart, Jan-Michael Peters, Frank Buchholz \& Anthony A Hyman

Nat. Methods 5, 409-415 (2008).

In the version of this supplementary file originally posted online, the supplementary figure legends were missing. The error has been corrected online as of 30 July 2008. The authors also originally omitted an acknowledgment thanking Roberto Iacone for helpful discussions in setting up the 96-well format procedure. 